УДК 621.923

DOI 10.36910/6775-2313-5352-2020-17-15

Новіков $^{1}$ Ф. В., Д. т. Н., Полянський ${ }^{2}$ В. І., к. т. н.

${ }^{1}$ Харківський національний економічний університет ім. С. Кузнеця, м. Харків, Україна

${ }^{2}$ ТОВ «Імперія металів», м. Харків, Україна

\title{
ВИЗНАЧЕННЯ УМОВ ПІДВИЩЕННЯ ЯКОСТІ МЕХАНІЧНОЇ ОБРОБКИ ЗА ТЕМПЕРАТУРНИМ КРИТЕРІЕМ
}

В роботі розглянуто питання підвищення якості механічної обробки за температурним критерісм складнопрофільної формуючої оснастки для харчової промисловості. Виконано чисельні розрахунки параметрів теплового процесу при шліфуванні, в якому припуск, щяо знімається, представлено набором адіабатичних стержнів, які перерізаються иліфувальним кругом. Встановлено, що час нагрівання адіабатичного стержня може бути до 10 разів менше часу його контакту з кругом при шліфуванні. Це пов'язано з тепловим насиченням поверхневого шару оброблюваної деталі. Доведено, що основна частка тепла, яка утворюється при шліфуванні, йде в стружки. Показано, що урахування перерізання адіабатичного стержня шліфувальним кругом забезпечує зменшення температури різання більш ніж в два рази. Це дозволяс по-новому підходити до вибору оптимального часу контакту шліфувального круга з оброблюваною деталлю й, відповідно, параметрів режиму шліфування та характеристик круга, виходячи з обмежень за температурою різання. Показано, що домогтися ще більшого зменшення температури різання можна в умовах лезової обробки сучасними збірними твердосплавними й керамічними ріжучими інструментами зі зносостійкими покриттям.

Ключові слова: шліфування, лезова обробка, формуюча оснастка, температура різання, якість обробки, ріжучі інструменти зі зносостійкими покриттями.

Постановка проблеми в загальному вигляді та їі зв'язок з важливішими науковими i практичними задачами. Із застосуванням на підприємствах України сучасних металорізальних верстатів 3 ЧПУ типу «обробний центр» зарубіжного виробництва та прогресивних збірних ріжучих твердосплавних $\mathrm{i}$ керамічних лезових інструментів зі зносостійкими покриттями з'явилася можливість суттєвого підвищення якості, точності й продуктивності обробки, виготовлення високоточних деталей машин. У зв'язку з цим в даний час на машинобудівних підприємствах України відбувається технічне переозброєння виробництва новими технологіями механічної обробки, обладнанням i ріжучими інструментами. В результаті продукція, що виготовляється, за якістю й собівартістю стає цілком конкурентоспроможною на економічних ринках. Це відкриває нові перспективи створення високоефективної машинобудівної продукції.

Як показує практика, не зважаючи на високу вартість сучасних імпортних металорізальних верстатів та інструментів, вони досить швидко окупаються й забезпечують високий прибуток підприємству. Особливо це відноситься до виготовлення складнопрофільної формуючої оснастки для харчової промисловості в ВАТ «Імперія металів» (м. Харків), який $\epsilon$ лідером серед провідних учасників даного ринку. Його частка складає понад $50 \%$ виробництва оснастки серед країн СНД. Завдяки застосуванню нових сучасних металорізальних верстатів 3 ЧПУ та ріжучих інструментів зі зносостійкими покриттями освоєно виробництво основних видів формуючої оснастки для харчової промисловості. Разом з тим, із застосуванням нових важкооброблюваних матеріалів і підвищенням вимог до якості, точності й продуктивності механічної обробки формуючої оснастки виникає необхідність подальшого вдосконалення технологій іiі виготовлення. Актуальною стає проблема науково обгрунтованого вибору умов підвищення якості та продуктивності обробки за рахунок зниження теплової й силової напруженостей механічної обробки та, відповідно, зниження температури різання.

Аналіз останніх досягнень і публікацій. Відомі аналітичні рішення щодо визначення температури різання при шліфуванні та лезовій обробці отримані на основі використання класичного диференціального рівняння теплопровідності матеріалів для сталого й несталого в часі режимів різання [1 - 4]. Це відкрило нові можливості науково обгрунтованого аналізу умов зменшення температури різання й відповідно підвищення якості та продуктивності обробки. Однак отримані рішення справедливі для цілком конкретних методів механічної обробки й не

๑) Новіков Ф. В., д. Т. н., Полянський В. І., к. т. н. 
дозволяють однозначно з єдиних позицій встановити температуру різання при шліфуванні та лезовій обробці.

$\mathrm{B}$ роботах $[5,6]$ запропоновано теоретичний підхід до аналітичного розрахунку температури різання при шліфуванні 3 урахуванням перерізання адіабатичних стержнів шліфувальним кругом. Щоб уточнити отримане рішення, в даній роботі поставлено задачу чисельного розрахунку температури різання при шліфуванні з урахуванням перерізання адіабатичних стержнів шліфувальним кругом на основі аналітичної залежності для визначення глибини проникнення тепла в поверхневий шар оброблюваної деталі при шліфуванні, тобто глибини проникнення тепла в розглянутий адіабатичний стержень [6]:

$$
l_{2}=\sqrt{\frac{2 \cdot \lambda \cdot \tau}{c \cdot \rho}}
$$

де $\tau-$ час нагріву адіабатичного стержня при його перерізанні, с.

Мета роботи - теоретичне обгрунтування умов суттєвого підвищення якості механічної обробки на основі зменшення температури різання на фінішних операціях.

Викладення основного матеріалу. Для зручності розрахунків рівномірний рух теплового джерела уздовж адіабатичного стержня зі швидкістю $V_{\text {різ }}$ слід розглядати періодичним з кроком $V_{\text {різ }} \cdot d \tau$, де $d \tau$ - нескінченно малий час, с. Тоді глибина проникнення тепла в адіабатичний стержень за час $d \tau$ визначиться:

$$
l_{2_{0}}=\sqrt{\frac{2 \cdot \lambda}{c \cdot \rho} \cdot d \tau} .
$$

У зв'язку з перерізанням частини адіабатичного стержня довжиною $V_{\text {різ }} \cdot d \tau$ глибина проникнення тепла в адіабатичний стержень зменшується на величину $V_{p i з} \cdot d \tau$ й дорівнює:

$$
l_{2_{1}}=\sqrt{\frac{2 \cdot \lambda}{c \cdot \rho} \cdot d \tau}-V_{p i 3} \cdot d \tau=\sqrt{\frac{2 \cdot \lambda}{c \cdot \rho} \cdot \tau_{1}},
$$

де $\tau_{1}$ - час нагрівання адіабатичного стержня при його перерізанні на величину $V_{p i s} \cdot d \tau$, c.

За умови $\alpha=\frac{V_{p i 3} \cdot d \tau}{l_{2_{0}}}<1$ маємо: $\tau_{1}=\frac{c \cdot \rho}{2 \cdot \lambda} \cdot\left(\sqrt{\frac{2 \cdot \lambda}{c \cdot \rho} \cdot d \tau}-V_{p i 3} \cdot d \tau\right)^{2}=d \tau \cdot(1-\alpha)^{2}$.

Як видно, справедлива умова $\tau_{1}<d \tau$, що призводить до зменшення параметра $l_{2_{1}}$ :

$$
l_{2_{1}}=\sqrt{\frac{2 \cdot \lambda}{c \cdot \rho} \cdot d \tau \cdot(1-\alpha)^{2}}=l_{2_{0}} \cdot(1-\alpha) .
$$

При другому кроці переміщення теплового джерела на величину $V_{p i s} \cdot d \tau$ :

$$
l_{2_{2}}=\sqrt{\frac{2 \cdot \lambda}{c \cdot \rho} \cdot\left(d \tau+\tau_{1}\right)}-V_{p i 3} \cdot d \tau=\sqrt{\frac{2 \cdot \lambda}{c \cdot \rho} \cdot \tau_{2}} .
$$

Звідки

$$
\tau_{2}=\frac{c \cdot \rho}{2 \cdot \lambda} \cdot\left(\sqrt{\frac{2 \cdot \lambda}{c \cdot \rho} \cdot\left(d \tau+\tau_{1}\right)}-V_{p i 3} \cdot d \tau\right)^{2}=d \tau \cdot\left(\sqrt{1+\frac{\tau_{1}}{d \tau}-\alpha}\right)^{2} .
$$

Аналогічно визначено:

$$
\begin{aligned}
& l_{2_{n}}=\sqrt{\frac{2 \cdot \lambda}{c \cdot \rho} \cdot \tau_{n}}=\sqrt{\frac{2 \cdot \lambda}{c \cdot \rho} \cdot\left(d \tau+\tau_{n-1}\right)}-V_{p i 3} \cdot d \tau ; \\
& \frac{\tau_{n}}{d \tau}=\left(\sqrt{1+\frac{\tau_{n-1}}{d \tau}}-\alpha\right)^{2}
\end{aligned}
$$


де $\tau_{n}, \tau_{n-1}-$ час нагрівання адіабатичного стержня при його перерізанні, відповідно, на величини $n \cdot V_{p i з} \cdot d \tau$ й $(n-1) \cdot V_{p і з} \cdot d \tau, \mathrm{c}$.

Безрозмірна величина $\alpha$ може змінюватися в межах: $0 \ldots 1$. У випадку $\alpha=0,2$ залежність (8) набуває вигляду:

$$
\frac{\tau_{n}}{d \tau}=\left(\sqrt{1+\frac{\tau_{n-1}}{d \tau}}-0,2\right)^{2} .
$$

Початкове значення $\tau_{1} / d \tau$ визначається із залежності (9) і дорівнює 0,64 . Виходячи із залежності (9), отримано $\tau_{2} / d \tau=1,1677$. Після підстановки в залежність (9) даного значення отримано: $\tau_{3} / d \tau=1,6187$. На рис. 1 наведено розрахункові значення $\tau_{n} / d \tau$, які зі збільшенням кількості кроків $n$ безперервно збільшуються, асимптотично наближаючись до певних сталих (максимальних) значень.

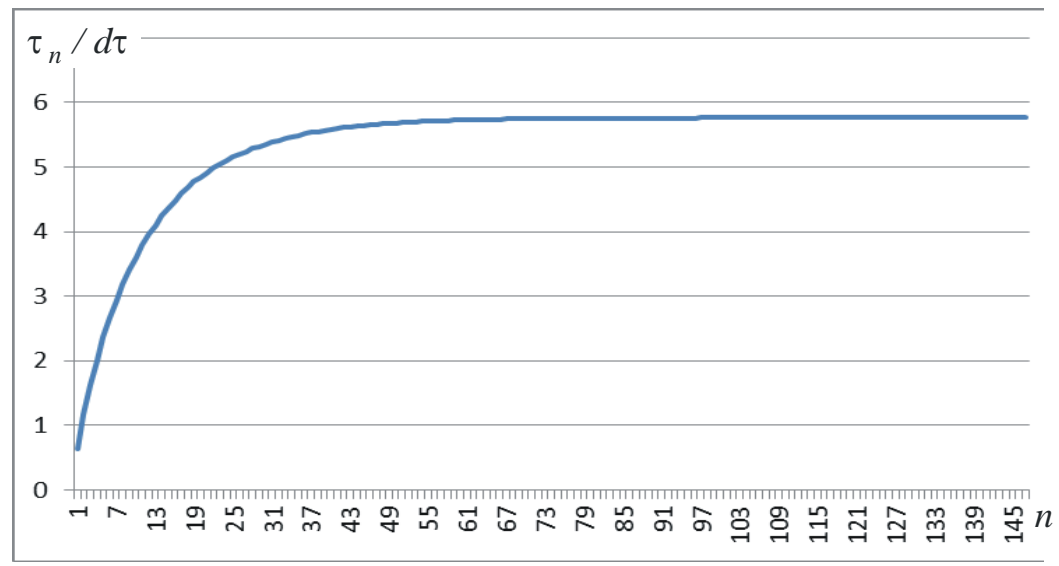

Рис. 1. Залежність $\tau_{n} / d \tau$ від $n$

Для визначення значення $\tau_{n}$ необхідно знати значення $d \tau$, яке можна встановити із залежності $\alpha=\frac{V_{p i 3} \cdot d \tau}{l_{2_{0}}}$. Тоді $d \tau=\frac{2 \cdot \lambda}{c \cdot \rho} \cdot\left(\frac{\alpha}{V_{p i 3}}\right)^{2}$.

Приймаючи вихідні дані для шліфування сталі ШХ15: коефіцієнт температуропровідності $a=\frac{\lambda}{c \cdot \rho}=8,4 \cdot 10^{-6} \mathrm{~m}^{2} / \mathrm{c} ; V_{p i 3}=3,33 \mathrm{mм} / \mathrm{c} ; \alpha=0,2$, отримано: $d \tau=0,0605$ c.

На рис. 2 наведено розрахункові значення $\tau_{n}$, які отримані шляхом множення значень $\tau_{n} / d \tau$ на значення $d \tau=0,0605$ с з використанням програмного продукту Компас 3D. Як видно, розрахункові значення $\tau_{n}$ (аналогічні значенням $\tau_{n} / d \tau$ ) зі збільшенням кількості кроків $n$ безперервно збільшуються, асимптотично наближаючись до певних сталих (максимальних) значень. 


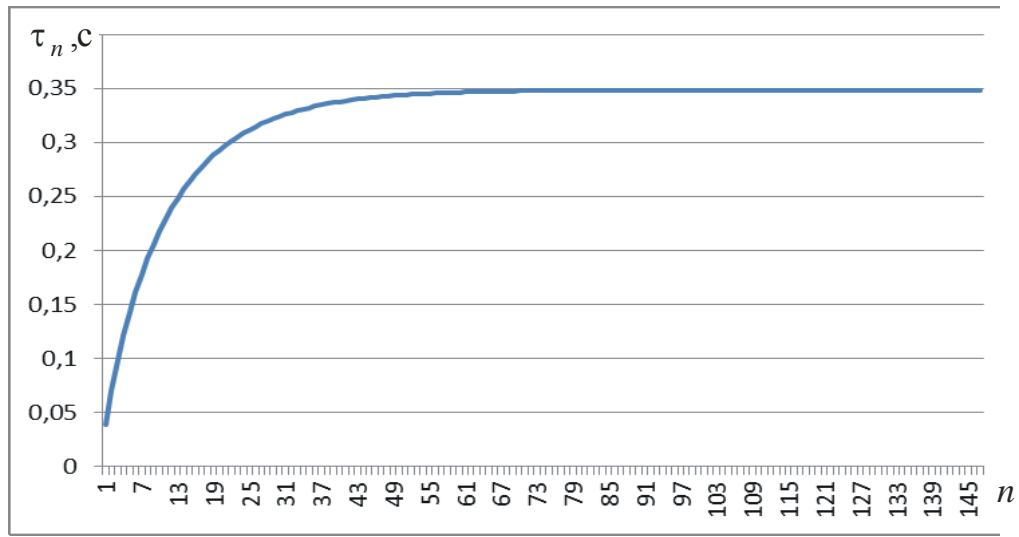

Рис. 2. Залежність $\tau_{n}$ від $n$

На рис. 3 показано характер зміни часу нагріву адіабатичного стержня при його перерізанні $\tau_{n}$ від часу контакту шліфувального круга 3 адіабатичним стержнем (часу перерізання шліфувальним кругом адіабатичного стержня) $\tau=n \cdot d \tau$. У цьому випадку зі збільшенням часу $\tau$ час $\tau_{n}$ змінюється аналогічно залежності $\tau_{n}$ від $n$ (рис. 2 ).

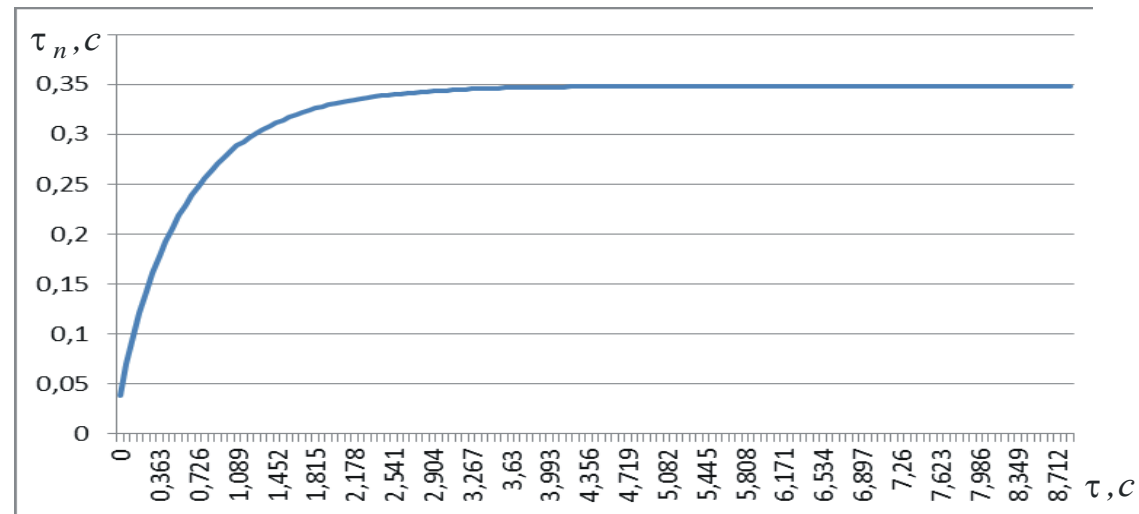

Рис. 3. Залежність $\tau_{n}$ від $\tau$

Отриманий результат показує на те, що час нагрівання адіабатичного стержня може бути значно менше (до 10 разів) часу його контакту з шліфувальним кругом при шліфуванні. Тому запропонований теоретичний підхід, заснований на урахуванні перерізання адіабатичних стержнів шліфувальним кругом в процесі шліфування, дозволяє уточнити відомі рішення й наблизити розрахункову схему шліфування до реальних умов обробки. Виходячи із залежності для визначення роботи шліфування $A=N \cdot \tau$ (де $N$ - потужність шліфування, Вт), відношення $\tau_{n} / \tau$ дорівнює відношенню кількості тепла, що йде в адіабатичний стержень в процесі його перерізання шліфувальним кругом, до загальної кількості тепла, що виділяється в процесі шліфування. Отже, зі збільшенням часу $\tau$ кількість тепла, що йде в адіабатичний стержень (в поверхневий шар оброблюваної деталі), зменшується, а кількість тепла, що йде в стружки, що утворюються, збільшується. Розрахунками встановлено, що в цьому випадку частка тепла, яка йде в адіабатичний стержень, приймає достатньо малі значення - всього кілька відсотків. Це надзвичайно важливий результат, який вказує на можливість забезпечення високоякісної обробки в умовах високопродуктивного глибинного шліфування, яке характеризується достатньо великими значеннями часу контакту шліфувального круга 3 адіабатичним стержнем $\tau$.

Очевидно, в умовах багатопрохідного шліфування, яке характеризується достатньо малими значеннями часу $\tau$, відношення $\tau_{n} / \tau$ приймає значення, близькі до одиниці. У цьому випадку фактично все тепло, яке утворюється в процесі шліфування, йде в адіабатичний стержень, тобто в оброблювану деталь. В стружки йде невелика частка тепла. За певних умов обробки це може призвести до утворення на оброблюваній поверхні різних температурних 
дефектів, що має місце на операціях шліфування. Тому для визначення оптимальних умов шліфування з точки зору забезпечення високоякісної та високопродуктивної обробки необхідно знати оптимальне відношення $\tau_{n} / \tau$, при якому температура різання при шліфуванні не перевищує граничне значення.

Використовуючи розрахункові значення часу нагріву адіабатичного стержня при його перерізанні $\tau_{n}$, на рис. 4 наведено розрахункові значення глибини проникнення тепла в адіабатичний стержень $l_{2_{n}}=\sqrt{2 a \cdot \tau_{n}}$ при шліфування сталі ШХ15 (коефіцієнт температуропровідності $\left.a=\lambda /(c \cdot \rho)=8,4 \cdot 10^{-6} \mathrm{~m}^{2} / \mathrm{c}\right)$.

Як видно, зі збільшенням часу контакту шліфувального круга з адіабатичним стержнем $\tau$ до певного значення параметр $l_{2_{n}}$ досягає граничного значення, що відповідає стану теплового насичення поверхневого шару оброблюваної деталі, й залишається постійним. Отримане рішення вказує, по-перше, на можливість суттєвого зменшення параметра $l_{2_{n}}$ в умовах багатопрохідного шліфування, яке характеризується невеликими значеннями часу, що дозволяє забезпечити високоякісну обробку. По-друге, вказує на можливість суттєвого збільшення продуктивності обробки в умовах глибинного шліфування, коли збільшення часу $\tau$ не призводить до збільшення параметра $l_{2_{n}}$ й зниження якості обробки.

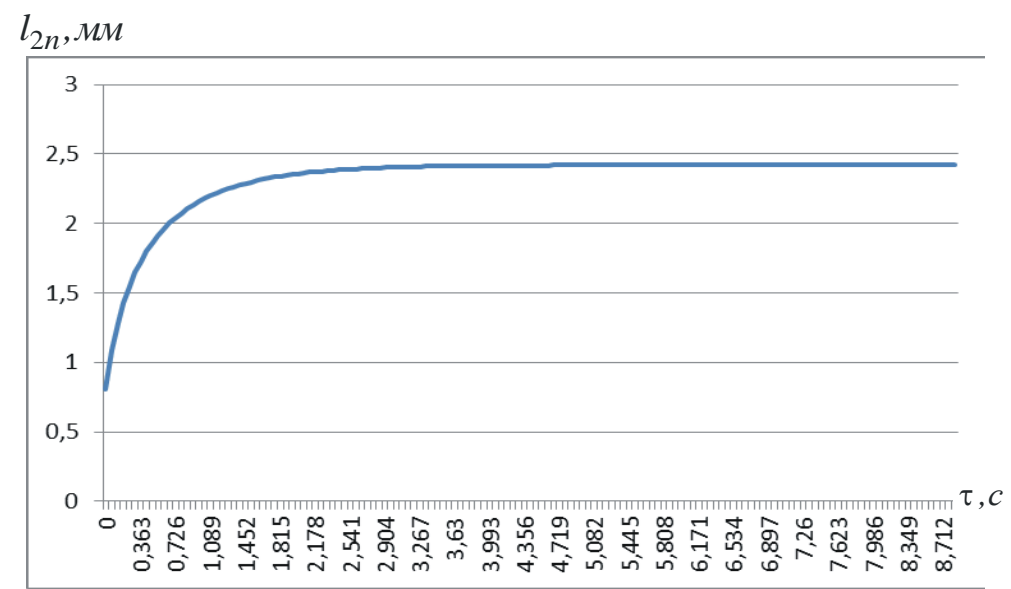

Рис. 4. Залежність $l_{2_{n}}$ від $\tau$

Для остаточного прийняття рішення про вибір оптимального відношення $\tau_{n} / \tau$ необхідно знати характер зміни температури шліфування $\theta$ від часу $\tau$. Тому, використовуючи розрахункові значення $l_{2_{n}}$, на рис. 5 наведено розрахункові значення температури шліфування $\theta=q \cdot l_{2_{n}} / \lambda$, отримані з урахуванням залежностей для визначення щільності теплового потоку $q=\sigma \cdot V_{p i 3}\left(\mathrm{BT} / \mathrm{M}^{2}\right) \quad$ та умовного напруження різання $\sigma=2 \cdot \sigma_{c m} / K_{p i 3}\left(\mathrm{H} / \mathrm{m}^{2}\right) \quad[6]$, де $\sigma=2 \sigma_{c m} / K_{p i 3} ; \sigma_{c m}-$ межа міцності на стиск оброблюваного матеріалу (для сталі ШХ15: $\left.\sigma_{c m}=2000 \mathrm{H} / \mathrm{Mm}^{2}\right) ; K_{\text {різ }}=0,4-$ коефіцієнт різання при шліфуванні. Тоді $\sigma=1010 \mathrm{H} / \mathrm{m}^{2}$. Швидкість різання $V_{p i з}=3,33 \mathrm{~mm} / \mathrm{c}$, коефіцієнт теплопровідності оброблюваного матеріалу $\lambda=42 \mathrm{Bт} /($ м градус).

При лезовій обробці можна ще значніше зменшити температуру різання за рахунок зменшення умовного напруження різання $\sigma=2 \cdot \sigma_{c m} / K_{p i з}$, оскільки коефіцієнт різання $K_{p i з}$ приймає значно більші значення, ніж при шліфуванні. Для цього необхідно забезпечити високу різальну здатність інструменту, наприклад, за рахунок нанесення на його робочі поверхні зносостійких покриттів, які зменшують знос інструменту та інтенсивність тертя в зоні різання. 


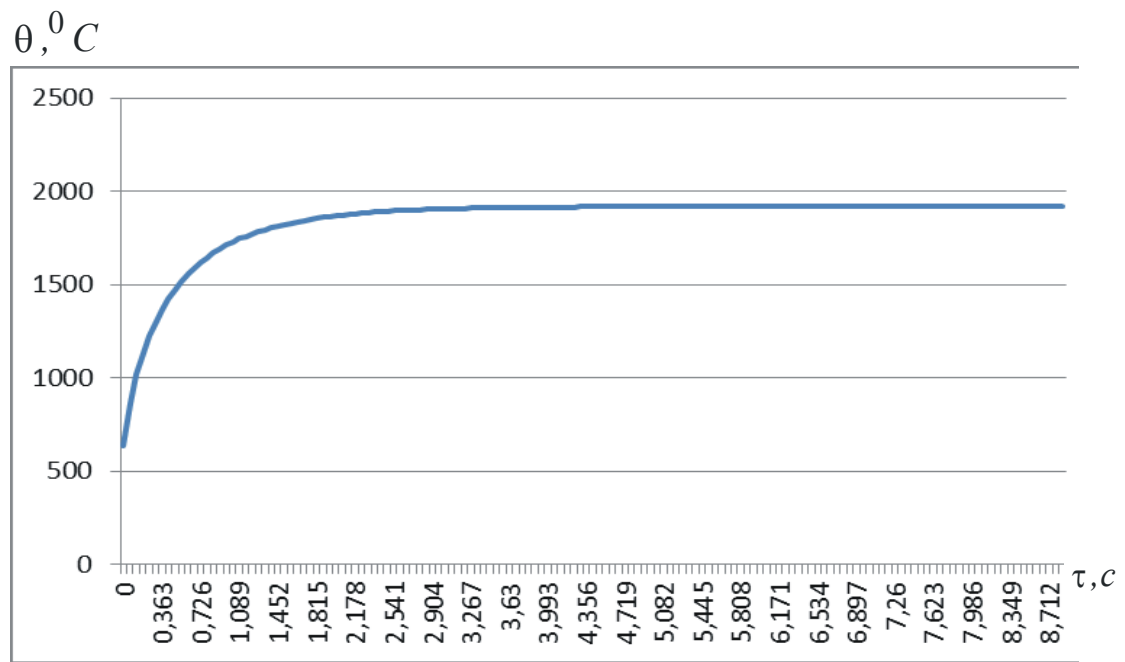

Рис. 5. Залежність $\theta$ від часу $\tau$

Як видно, зі збільшенням часу контакту шліфувального круга з адіабатичним стержнем $\tau$ температура різання при шліфуванні $\theta$ спочатку збільшується до певного значення, потім стабілізується й залишається постійною. Отже, з точки зору забезпечення високопродуктивної обробки доцільно застосовувати глибинне шліфування, що характеризується невеликими значеннями відношення $\tau_{n} / \tau$. При цьому необхідно стабілізувати температуру різання при шліфуванні $\theta$ на заданому рівні, який вилучає термічне руйнування оброблюваного матеріалу. Однак, найбільш просто реалізувати задану температуру різання при шліфуванні $\theta$ можна в умовах багатопрохідного шліфування, тобто при відносно невеликих значеннях відношення $\tau_{n} / \tau$, що і передбачає широке застосування на практиці цієї схеми шліфування. В цьому випадку можна гарантовано забезпечити високі показники якості та продуктивності обробки.

При лезовій обробці можна ще значніше зменшити температуру різання за рахунок зменшення умовного напруження різання $\sigma=2 \cdot \sigma_{c m} / K_{p i з}$, оскільки коефіцієнт різання $K_{p i з}$ приймає значно більші значення, ніж при шліфуванні. Для цього необхідно забезпечити високу різальну здатність інструмента, наприклад, за рахунок нанесення на його робочі поверхні зносостійких покриттів, які зменшують знос інструменту та інтенсивність тертя в зоні різання. Це дозволить підвищити якість обробки, вилучити утворення на оброблених поверхнях виробів температурних дефектів. У ряді випадків це дозволить також відмовитися від процесу шліфування й остаточну обробку проводити ріжучими лезовими інструментами, наприклад, сучасними збірними твердосплавними й керамічними ріжучими інструментами зі зносостійкими покриттями закордонного виробництва, що підтверджується їх широким застосуванням на операціях фінішної механічної обробки складнопрофільної формуючої оснастки для харчової промисловості [7,8].

Таким чином встановлено, що урахування руху теплового джерела уздовж адіабатичного стержня в процесі шліфування дозволило уточнити відоме рішення про характер зміни параметрів $l_{2}$ i $\theta$ зі збільшенням часу $\tau$ та виявити нові закономірності їх формування, пов'язані з досягненням стану температурного насичення поверхневого шару оброблюваної деталі й стабілізацією в часі параметрів $l_{2}$ i $\theta$. Це відкриває нові технологічні можливості інтенсифікації процесу механічної обробки за умови одночасного забезпечення високої якості оброблюваних поверхонь. Отримані теоретичні рішення можуть бути використані для удосконалення процесів шліфування та лезової обробки на фінішних операціях.

Висновки. В роботі розглянуто питання підвищення якості механічної обробки за температурним критерієм складнопрофільної формуючої оснастки для харчової промисловості. Виконано чисельні розрахунки параметрів теплового процесу при шліфуванні. Визначено час нагрівання адіабатичних стержнів, якими умовно представлений припуск, що знімається, та які перерізаються шліфувальним кругом в процесі шліфування. Встановлено, що час нагрівання адіабатичного стержня може бути до 10 разів менше часу його контакту 3 шліфувальним кругом при шліфуванні. Це пов'язано $з$ тим, що час нагрівання адіабатичного стержня 3 часом 
обробки збільшується, асимптотично наближаючись до максимального значення, що визначається умовою теплового насичення поверхневого шару оброблюваної деталі. Розрахунками встановлено, що за таким самим законом змінюються температура різання й глибина проникнення тепла в поверхневий шар оброблюваної деталі, що дозволяє оцінити товщину дефектного шару оброблюваної деталі. Доведено, що значна частка тепла, яка утворюється при шліфуванні, надходить до стружки, що утворюються, а в оброблювану деталь надходить менша частка тепла. Показано, що урахування перерізання адіабатичного стержня шліфувальним кругом забезпечує зменшення температури різання більш ніж в два рази. Це дозволяє по-новому підходити до вибору оптимального часу контакту шліфувального круга 3 оброблюваною деталлю й, відповідно, параметрів режиму шліфування та характеристик круга, виходячи 3 обмежень за температурою різання. Показано, що домогтися ще більшого зменшення температури різання можна в умовах лезової обробки сучасними збірними твердосплавними й керамічними ріжучими інструментами зі зносостійкими покриттями. Це досягається за рахунок забезпечення високої різальної здатності інструмента та зменшення його зносу й інтенсивності тертя в зоні різання.

Перспективи подальшої роботи в даному напряму. В подальших дослідженнях необхідно теоретично й експериментально визначити температуру різання, яка виникає при обробці сучасними лезовими ріжучими збірними твердосплавними й керамічними ріжучими інструментами зі зносостійкими покриттями, та обгрунтувати умови іiі зменшення 3 ціллю забезпечення високоякісної обробки деталей машин.

\section{Інформаційні джерела}

1. Якимов А. В. Оптимизация процесса шлифования / А. В. Якимов. - Москва : Машиностроение, 1975. - 175 с.

2. Моделирование систем: монография / Г. А. Оборский, А. Ф. Дащенко, А. В. Усов и др. Одесса: Астропринт, 2013. - 664 с.

3. Сизый Ю. А. Динамика и теплофизика шлифования / Ю. А. Сизый, Д. В. Сталинский. Харьков: ГП УкрНТЦ "Энергосталь", 2016. - 448 с.

4. Глубинное шлифование деталей из труднообрабатываемых материалов / С. С. Силин, В. А. Хрульков, А. В. Лобанов, Н. С. Рыкунов. - Москва : Машиностроение, 1984. - 62 с.

5. Физико-математическая теория процессов обработки материалов и технологии машиностроения / Под общ. ред. Ф. В. Новикова и А. В. Якимова. В десяти томах. - Одесса: ОНПУ, 2003. - Т. 2. "Теплофизика резания материалов". - 625 с.

6. Новиков Ф. В. Основы математического моделирования технологических процессов механической обработки: монография / Ф. В. Новиков. - Д. : ЛИРА, 2018. - 400 с.

7. Полянский В. И. Расчет температуры шлифования с учетом баланса тепла, уходящего в стружки и обрабатываемую деталь / В. И. Полянский // Сучасні технології в машинобудуванні: зб. наук. праць. - Вип. 13 / редкол.: В. О. Федорович (голова) [та ін.]. - Харків : НТУ «ХПІ», 2018. - С. 51-59.

8. Полянский В. И. Условия повышения качества механической обработки деталей из высокопрочных хрупких материалов / В. И. Полянский // Вісник Харківського національного технічного університету сільського господарства імені Петра Василенка. - Харків: ХНТУСГ, 2011. - Вип. 118. - С. 178-184.

Новиков $^{1}$ Ф. В., Д. Т. Н., Полянский ${ }^{2}$ В. И., к. т. н.

${ }^{1}$ Харьковский национальный экономический университет имени Семена Кузнеца, г. Харьков, Украина

${ }^{2} \mathrm{OOO} \mathrm{«Империя} \mathrm{металлов»,} \mathrm{г.} \mathrm{Харьков,} \mathrm{Украина}$

\section{ОПРЕДЕЛЕНИЕ УСЛОВИЙ ПОВЫШЕНИЯ КАЧЕСТВА МЕХАНИЧЕСКОЙ ОБРАБОТКИ ПО ТЕМПЕРАТУРНОМУ КРИТЕРИЮ}

В работе рассмотрены вопросы повышения качества механической обработки по температурному критерию сложнопрофильной формирующей оснастки для пищевой промышленности. Выполнены численные расчеты параметров теплового прочесса при шлифовании, в котором снимаемый припуск представлен набором адиабатических стержней, которые перерезаются шлифовальным кругом. Установлено, что время нагревания 
адиабатического стержня может быть до 10 раз меньше времени его контакта с кругом при илифовании. Это связано с тепловым насыщением поверхностного слоя обрабатываемой детали. Доказано, что основная доля тепла, которое образуется при илифовании, уходит в стружки. Показано, что учет перерезания адиабатического стержня илифовальным кругом обеспечивает уменьшение температуры резания более чем в два раза. Это позволяет поновому подходить $\kappa$ выбору оптимального времени контакта илифовального круга $c$ обрабатываемой деталью $u$, соответственно, параметров режима шилфования $u$ характеристик круга, исходя из ограничений по температуре резания. Показано, что добиться еще большего уменьшения температуры резания можно в условиях лезвийной обработки современными сборными твердосплавными и керамическими режущими инструментами с износостойкими покрытиями.

Ключевые слова: илифование, лезвийная обработка, формирующая оснастка, температура резания, качество обработки, режущие инструменты с износостойкими покрытиями.

Novikov $^{1}$ F. V., Doctor of Technical Sciences, Polyansky² V. I., Ph.D.

${ }^{1}$ Simon Kuznets Kharkiv National University of Economics, Kharkiv, Ukraine

${ }^{2}$ LLC "Empire of metals", Kharkiv, Ukraine

\section{DETERMINATION OF CONDITIONS FOR IMPROVING THE QUALITY OF MACHINING BY TEMPERATURE CRITERIA}

The paper considers the issue of improving the quality of machining according to the temperature criterion of complex forming equipment for the food industry. Numerical calculations of the parameters of the thermal process during grinding are performed, in which the removed allowance is represented by a set of adiabatic rods, which are cut by a grinding wheel. It is established that the heating time of the adiabatic rod can be up to 10 times less than the time of its contact with the circle during grinding. This is due to the thermal saturation of the surface layer of the workpiece. It is proved that the main part of the heat generated during grinding goes to the chips. It is shown that taking into account the cutting of the adiabatic rod by the grinding wheel provides a reduction of the cutting temperature more than twice. This allows a new approach to choosing the optimal contact time of the grinding wheel with the workpiece and, accordingly, the parameters of the grinding mode and the characteristics of the wheel, based on the limitations of the cutting temperature. It is shown that it is possible to achieve even greater reduction of cutting temperature in the conditions of blade processing by modern prefabricated hard-alloy and ceramic cutting tools with a wear-resistant covering.

Keywords: grinding, blade processing, forming equipment, cutting temperature, processing quality, cutting tools with wear-resistant coatings. 